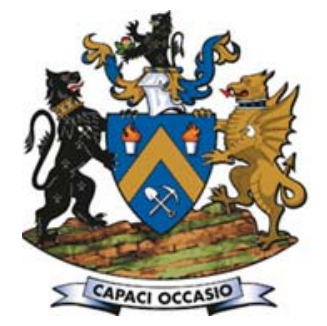

\title{
Application of geometallurgical modelling to mine planning in a copper-gold mining operation for improving ore quality and mineral processing efficiency
}

\author{
by C. Beaumont ${ }^{1}$ and C. Musingwini ${ }^{2}$
}

\section{Synopsis}

Kansanshi mine, located in northwestern Zambia, uses conventional openpit mining to produce primarily copper, with gold as a by-product. The ore is extracted from a deposit with highly complex mineralogical suites that are difficult to process, sometimes leading to poor recoveries. The mine was using an ore classification system called 'Mat-Type', which classified various ore types into 22 different quality categories, ranging from poor to good quality. Ore with poor recovery was classified as 'poor quality' ore and directed to long-term stockpiles. Due to a lack of proper integration between the technical and functional areas forming the mine value chain, Mat-Type unintentionally misclassified ore. A geometallurgical analysis was therefore undertaken to review Mat-Type and a new geometallurgical ore classification system, called 'OXMAT', was developed to replace MatType.

When implemented, OXMAT eliminated nine of the 22 ore categories and the remaining 13 ore categories could now be more accurately and consistently defined, leading to a significant change in the quantity of ore being mined. OXMAT demonstrated that within a defined test volume of the geological model, waste tonnes could be reduced by $19 \%$ while ore tonnes could be increased by $17 \%$. This paper therefore demonstrates the value created through integrated geometallurgical modelling.

\section{Keywords}

acid-soluble copper, total copper, gangue acid consumption, geometallurgical modelling, oxidation ratio, weathering domains.

\section{Introduction}

Kansanshi mine is located in northwestern Zambia, approximately $10 \mathrm{~km}$ north of the provincial capital Solwezi and about $160 \mathrm{~km}$ west of Nchanga mine in the Central African Copperbelt (Broughton and Hitzman, 2002). The location of Kansanshi mine relative to other major copper deposits in the Copperbelt is indicated in Figure 1.

Kansanshi mine uses conventional openpit mining methods to exploit copper- and gold-bearing veins hosted in a structurallycontrolled mineral deposit. Mining is carried out in two areas of the deposit, the Northwest and Main pits. A third area of the deposit, called Southeast Dome, is currently not being exploited (Figure 2).

Figure 3 illustrates an east-west crosssection of the Kansanshi mine grade control model through the Main Pit area of the deposit, created using assay and logging data to support geostatistical estimations of copper grade continuity. The model has been colourcoded based on total copper ( $\mathrm{TCu}$ ) grade ranges. The model also has mineralogical domains defined by ranges of oxidation intensity and associated mineralogy.

The Kansanshi deposit comprises a series of complex mineralogical suites that were formed through the interaction of geological, weathering, and oxidation processes.

Geophysical and geochemical processes resulted in the mineralization in the upper portion of the ore deposit being oxidized from a predominantly chalcopyrite, pyrrhotite, and pyrite assemblage to a suite of secondary copper sulphide minerals and primary copper oxide minerals, including bornite, digenite, chalcocite, malachite, tenorite, and chrysocolla. Where large subvertical fault structures cut across the deposit, these processes have affected the host rock and mineralization at much deeper levels. There is a high degree of variability in the composition of the mineral assemblages over short ranges, both laterally across the deposit and vertically within mineralized structures.

The mine has a complex metallurgical processing plant which is designed to primarily recover copper from different ore types. In order to treat the different ore types, there are three main metallurgical processes, all of which are served by a dedicated crusher and set of mills. These metallurgical processes are (Beaumont, 2016):

> Sulphide ore flotation

> Mixed ore flotation

> Oxide ore flotation followed by atmospheric acidic leaching, solvent extraction, and electrowinning (SX-EW).

1 Kansanshi Mining Company PLC, Solwezi, Zambia.

2 School of Mining Engineering, University of the Witwatersrand, South Africa.

(C) The Southern African Institute of Mining and Metallurgy, 2019. ISSN 2225-6253. Paper received Aug. 2018; revised paper received Oct. 2018. 


\section{Application of geometallurgical modelling to mine planning in a copper-gold mining operation}

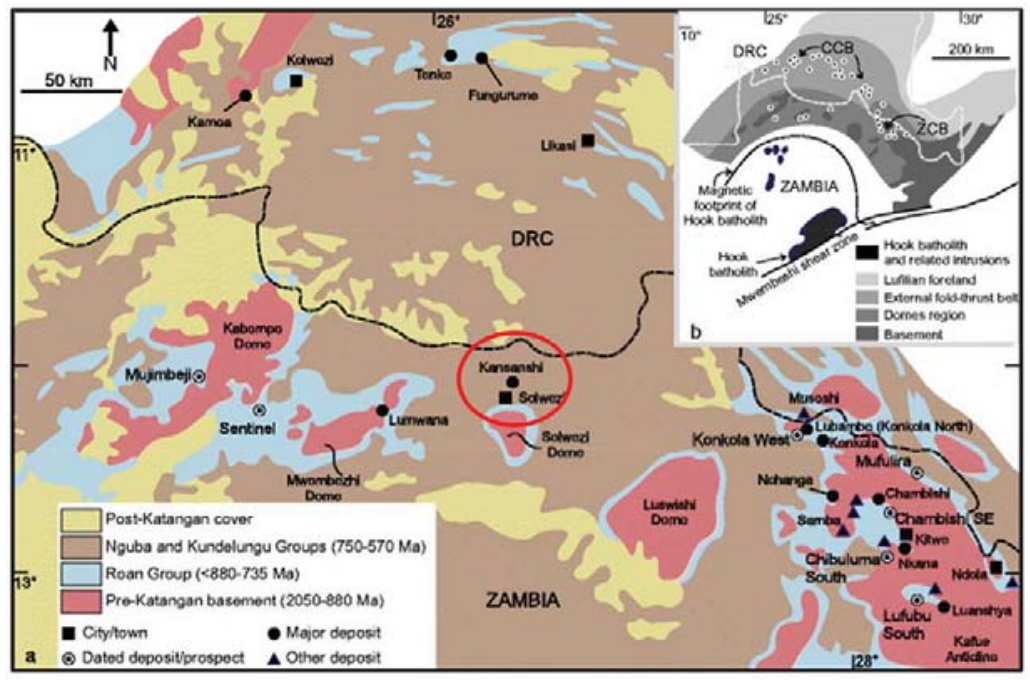

Figure 1-Map of major deposits in the Central African Copperbelt with the location of Kansanshi mine circled in red (Adapted from Silitoe et al., 2017)

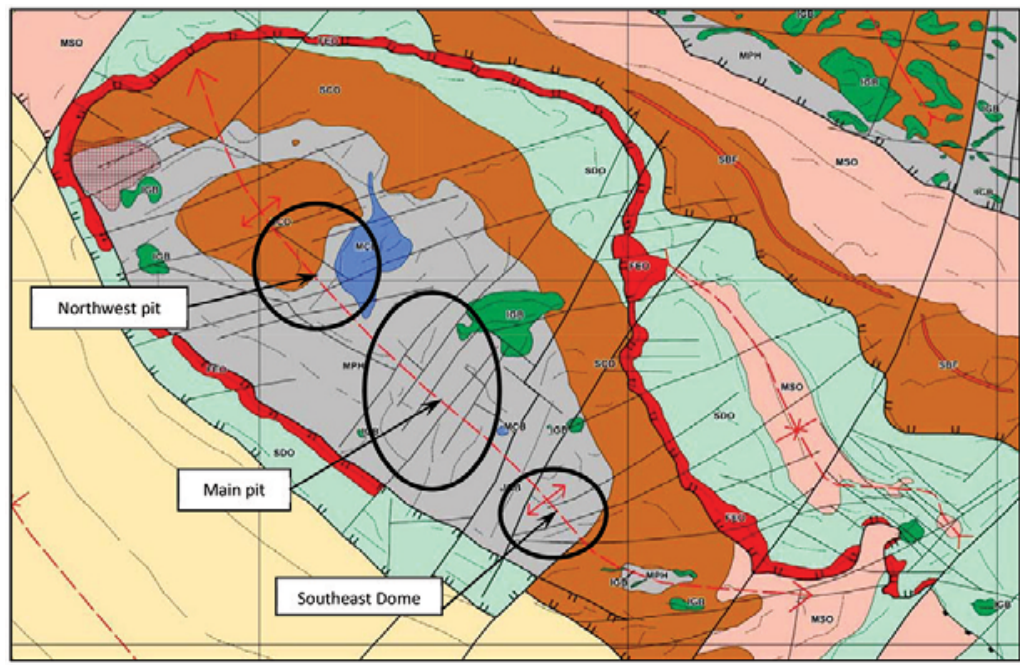

Figure 2-Geological map of the Kansanshi ore deposit (adapted from Wood, 2011)

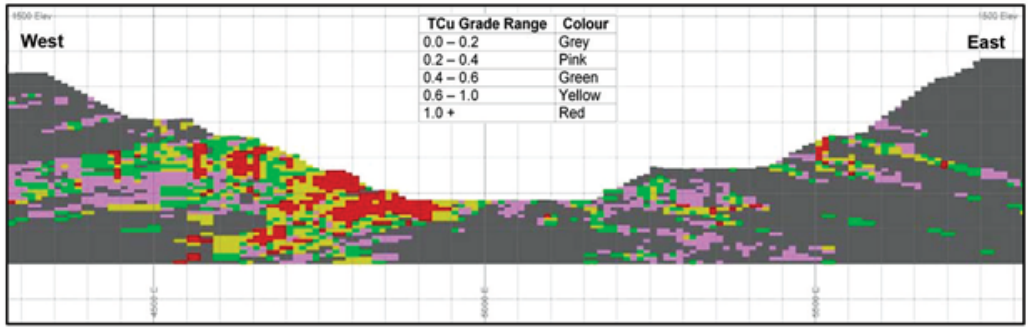

Figure 3-Cross section through the Main Pit portion of the Kansanshi mine grade control model, looking north

The sulphide flotation plant utilizes a standard flotation method to produce a copper and gold concentrate for smelting. The mixed flotation plant utilizes controlled potential sulphidization (CPS) to improve the recovery of secondary copper sulphide minerals or partially oxidized copper bearing minerals, also to produce a copper- and goldbearing concentrate for smelting. The oxide ore plant utilizes a standard flotation method producing a copper and gold concentrate for smelting. Tailings from the oxide ore flotation plant report to an atmospheric leach plant. Copper is leached from the oxide ore using concentrated sulphuric acid, and the pregnant solution is subjected to solvent extraction and electrowinning to produce a final copper cathode product. Gold is also recovered from all metallurgical circuits by centrifugal concentrators. The gold concentrate is upgraded by tabling and smelted to produce doré bars. 


\section{Application of geometallurgical modelling to mine planning in a copper-gold mining operation}

Some of the mineralogical suites are difficult to process in the metallurgical plant, leading to poor recoveries. A material type ore classification system called 'Mat-Type' was used to classify the various ore types based on a number of control parameters that would manage ore quality and ensure efficient and economic recovery of copper and gold. Ore containing mineral assemblages considered to be of 'poor quality' were directed to long-term stockpiles, which are scheduled for processing towards the end of the life of mine.

In 2015 a smelter was commissioned on the Kansanshi mine site. A by-product of the smelting process is sulphuric acid, which is a reagent that is critical to the oxide ore leaching process. The production of sulphuric acid from the smelter flue gas reduces the impact on local air quality. In addition, the cheap acid produced has a significant impact on the economic viability of some of the 'poor quality' oxide ore that was previously considered to be too expensive to process due to its high acid consumption in the leaching process.

It was therefore imperative that a review of the Mat-Type ore classification system be undertaken to determine how it could be improved through the application of geometallurgical modelling principles. The ultimate goal of the review was to establish if the value of the 'poor quality' ore could be realized sooner through better ore classification so that ore could be fed to the process plant directly rather than being stockpiled and reclaiming it at a later date. Better ore classification could potentially be achieved through an improved geometallurgical understanding that is integrated across the overall mine value chain.

\section{Methodology}

The review of the Mat-Type ore classification system required an understanding of holistically integrating multiple technical and functional areas across the entire mine value chain. It was therefore, important to develop a research methodology that would systematically address each of these areas in a manner that would maintain focus on the relevant data in the context of the overall project goal. To this end, the literature was reviewed for information on how geometallurgical investigations had been undertaken on other mineral deposits. This review demonstrated the need to investigate each aspect of the problem in a systematic manner, starting with the ore deposit characteristics and working forward, through each stage of the mine value chain to establish how each stage impacted consecutive stages.

This required mapping out the Mat-Type system as a flow chart to identify each of the decision-making points and the factors or assumptions applied at each of those points. Work could then be carried out to determine if any particular decision point, factor, or assumption was still relevant given the current, more thorough understanding of the deposit and mineral processing system. Through an iterative process, the modified decisions, factors, and assumptions were built into a separate flow chart which was code-named ' $O X M A T$ '. This allowed comparisons to be made between the Mat-Type and OXMAT systems to enable the determination of the scale of change caused by each modification as it was applied at each stage of the ore classification system.

\section{Geometallurgical modelling}

Bye (2011) described case studies where geometallurgical modelling has been used in the mining industry to overcome challenges arising from ore variability and to generate significant value-add. Bye (2011) and Chibaya (2013) broadly explained the concept of geometallurgy as a technical approach that integrates geology, mine design and planning, metallurgy, and environmental analysis with the aim of improving the understanding of available mineral resources for better extraction of the minerals of interest.

In the case of Kansanshi mine, the Mat-Type system was used for classifying the various ore types, ranging from 'poor quality' to 'good quality', into 22 different quality categories. It was found that due to poor integration between the technical operating silos that form the mine value chain, the Mat-Type ore classification system did not adequately consider geological, mineralogical, or metallurgical processes in an integrated way.

\section{Overview of the Mat-Type ore classification system}

The Mat-Type ore classification system was first introduced at Kansanshi mine in 2009. The system was designed with the following objectives (Beaumont, 2016):

> Separating oxide ore from sulphide ore and categorizing anything that was not sulphide or oxide as mixed float ore

> Applying a set of cut-off grades to categorize waste, marginal grade, low grade, and high grade for both sulphide ore and oxide ore

> Improving the 'quality' of the sulphide ore mill feed product by reducing the acid-soluble copper (ASCu) content to $<0.05 \%$

> Improving the 'quality' of the mixed float ore product by increasing the quantity of acid-insoluble copper (AICu) in the ore feed

$>$ Improving the 'quality' of the oxide ore product by increasing ASCu grades to $>0.6 \%$

> Managing the consumption of sulphuric acid $\left(\mathrm{H}_{2} \mathrm{SO}_{4}\right)$, which is an important yet costly reagent used in the oxide ore processing circuit

> Directing any ore that did not conform to the above quality control factors to appropriate long-term stockpiles.

Based on the objectives listed above, the Mat-Type ore classification system used a series of 'IF' statements to apply fixed grade limits and quality control parameters to determine ore that would be suitable to feed each of the three mineral processing circuits: sulphide flotation, mixed flotation, and oxide leach. Anything that was not suitable for the processing plant would be directed to a long-term stockpile. Figure 4 illustrates the calculation logic of the Mat-Type system, where, each of the 22 hexagonal boxes represents a specific ore type.

\section{Shortcomings of the Mat-Type ore classification system}

Through a systematic review of the Mat-Type ore classification system a number of key shortcomings were identified (Beaumont, 2016):

> A lack of ownership and management of the input data, and the absence of a formalized review process to ensure that data inputs remain fit-for-purpose under ever-changing circumstances 


\section{Application of geometallurgical modelling to mine planning in a copper-gold mining operation}

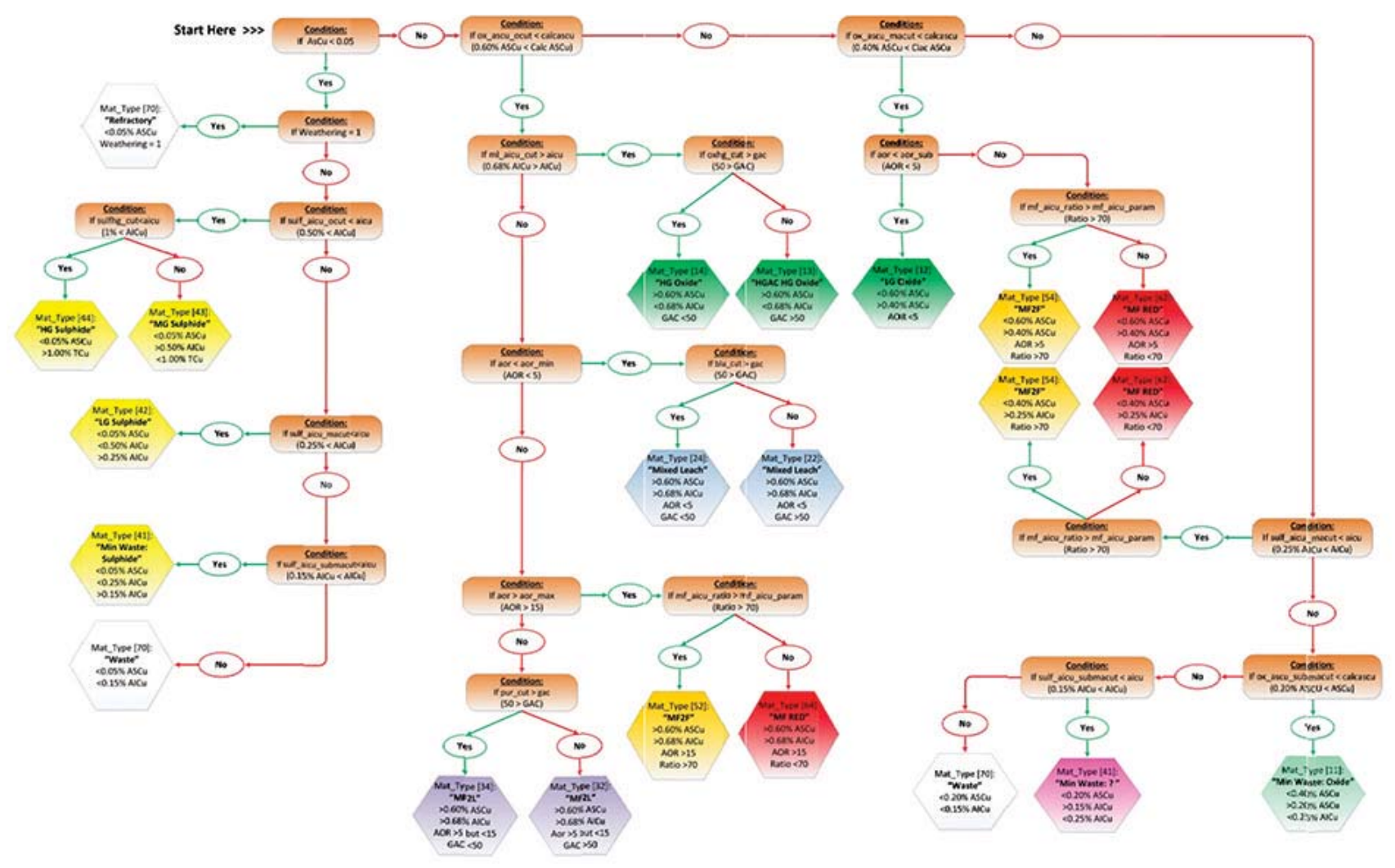

Figure 4-Flow chart representing the Mat-Type ore classification systyem calculatlion logic (Beaumont, 2016)

$>$ Lack of application of geological data to support the definition of certain ore categories

$>$ Application of inconsistent 'quality control' factors at various stages of the ore classification process.

\section{Development of an integrated approach to ore classification}

The Mat-Type ore classification system was developed by a consultancy firm in conjunction with the technical services team at Kansanshi mine. The key objective of the classification system was to direct the best quality and highest grade ore to the process plant in order to increase copper production. Once the system was developed it was handed over to the technical services team on site and implemented in early 2009. Given the simplistic understanding of the ore deposit at that time, there was no process to rigorously validate the Mat-Type ore classification system and fully understand how it was categorizing ore into the different types.

From 2010 to 2013, a large-scale mineral resource definition drilling programme was completed and a number of capital projects to upgrade and increase the throughput capacity of the metallurgical plant were also commissioned. During this time, operating costs, mineral royalties, and commodity prices changed. Following the publication of an updated Mineral Resource and Mineral Reserve statement and Life of Mine Optimization (LOM) plan in December 2012, the Kansanshi mine technical services team was asked to review the cut-off grades applied to the grade control model by the Mat-Type system. During this review it emerged that a number of other data inputs to and assumptions in the system also needed to be reviewed in the context of the improved understanding of the geology and mineralization of the deposit and of the metallurgical process.

A cross-functional team composed of geologists, mining engineers, and metallurgists was tasked to complete a thorough review of the entire Mat-Type ore classification system to ensure that it remained fit-for-purpose. Detailed technical discussions were promoted between stakeholders across the functional areas of the mine value chain, allowing the free flow of ideas and improved understanding of the orebody, the mining process, and the metallurgical process. This integration of knowledge and understanding between the key technical areas allowed for improved decisionmaking based on all of the available data. A cross-functional approach to the systematic review of available data was critical in supporting the development of a geometallurgical ore classification method.

\section{General impracticality}

The Mat-Type system was extremely complicated to use. Only four out of the 22 available ore categories could be used consistently on a daily basis to feed the process plant. Each day the mine geologist on duty would have to manually redirect ore from the digging face to the crusher based on a visual assessment of the characteristics of the material being mined. These manual re-directions were subjective. The intention of the Mat-Type system was to provide greater control over the quality of the ore reporting to the mineral processing circuit. However, the day-to-day reality was that there were so many quality control factors applied to the system that its consistency in application was questionable. 


\section{Application of geometallurgical modelling to mine planning in a copper-gold mining operation}

\section{The impact of weathering and oxidation on the in-situ ore}

The Mat-Type ore classification system used in situ weathering domains as a primary broad-scale criterion for grouping types of ore. The assumption was that each of the following three groups could be linked to a metallurgical process.

> Mineralization in highly weathered saprolite zones was considered to be suitable for the oxide process plant

> Mineralization in saprock zones was considered to be suitable for processing in the mixed ore flotation plant

> Mineralization contained in the fresh rock (unweathered areas) was considered to be suitable for the sulphide ore flotation plant.

However, the weathering process was not responsible for the chemical modification of ore minerals from the original chalcopyrite assemblage to secondary sulphide or primary oxide assemblages. This was the result of oxidation. The intensity of weathering and oxidation across the Kansanshi deposit is highly variable. Typically, in areas of intense weathering there is also intense oxidation. However, it was also observed that in deep-seated fault structures, where weathering was limited and the host lithology still remained largely intact, pods of moderately to highly oxidized mineralization could be found.

Through statistical analysis of raw sample data gathered from diamond drilling and reverse circulation drilling programmes a series of oxidation domains was defined. An oxidation ratio was calculated using Equation [1] and applied to the raw geological sample data. Assay values below $0.20 \%$ $\mathrm{TCu}$ were removed from this analysis to aid in interpretation. These results were plotted on a log histogram as presented in Figure 5.

$$
\text { Oxidation Ratio (Minrat) }=\frac{A S C u}{T C u}
$$

This exercise demonstrated that there were four distinct oxidation domains within the Kansanshi mineral deposit.
These domains could be defined as:

$>$ Ratio range <0.10: Fresh sulphide mineralization composed of chalcopyrite

$>$ Ratio range between $>0.10$ and $<0.15$ : Secondary copper sulphide mineralization composed of bornite, with minor amounts of covellite, digenite, and chalcopyrite

$>$ Ratio range between $>0.15$ and <0.50: Secondary copper sulphide mineralization composed of chalcocite, with minor covellite, digenite, and copper oxides such as tenorite and chrysocolla

$>$ Ratio range >0.50: Oxidized mineralization predominantly composed of malachite and chrysocolla with minor chalcocite, tenorite, cuprite, and native copper.

A pit wall mapping campaign undertaken in conjunction with re-logging of selected diamond drill core confirmed the spatial presence of these mineral groupings within the ranges of oxidation ratio specified above. This analysis demonstrated that it would be more appropriate to categorize ore types according to oxidation intensity and associated mineralogy rather than by weathering characteristics, as was then the practice in the Mat-Type ore classification system.

\section{Copper recovery modelling analysis}

Metallurgical recovery modelling for each of the process plant routes had typically been done in isolation owing to the view that each ore product and each mineral processing route was separate. The accepted logic was that higher ASCu grades in the sulphide flotation system led to poor recovery. A fixed cut-off grade of $0.05 \%$ ASCu was used to manage the quality of the sulphide ore in order to obtain the maximum copper recovery in the sulphide flotation plant. Ore with an ASCu $>0.05 \%$ would be directed to the mixed float circuit or a longterm stockpile.

Analysis was conducted to compare the recovery profiles of the sulphide and mixed float processes. The results of this analysis are presented in Figure 6. The analysis demonstrated that while ASCu values $>0.05 \%$ reduced

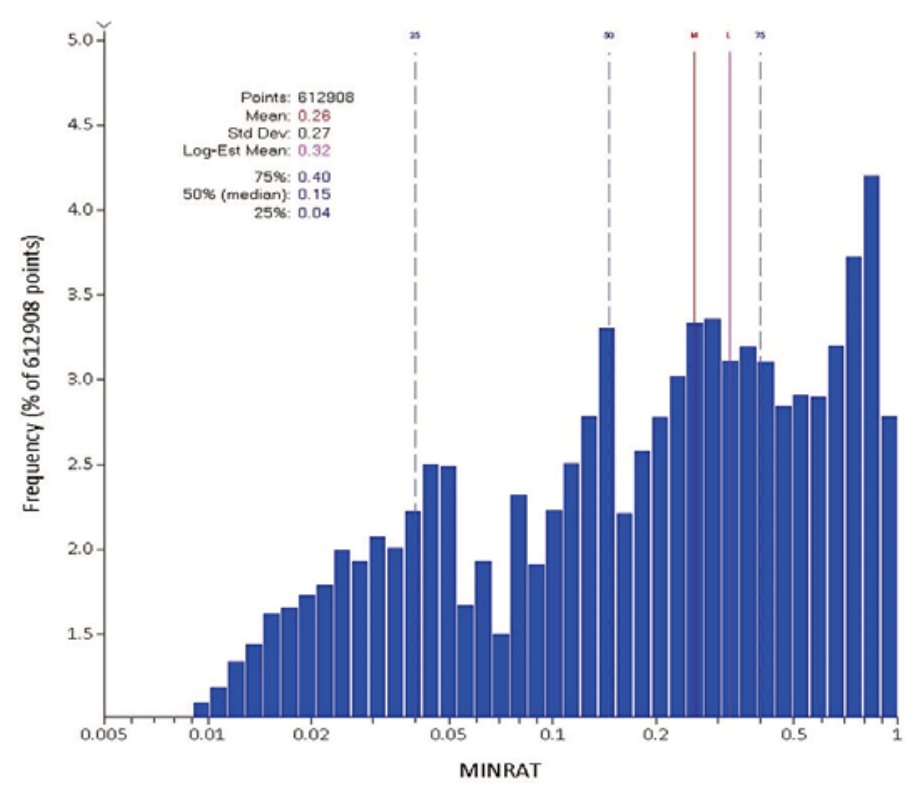

Figure 5-Log histogram of oxidation ratios for raw sample data from the Kansanshi ore deposit (Beaumont, 2017) 


\section{Application of geometallurgical modelling to mine planning in a copper-gold mining operation}

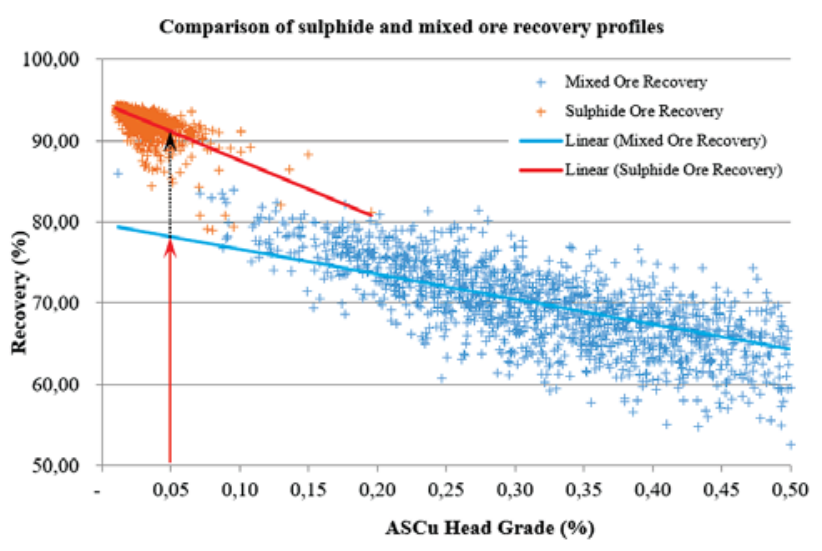

Figure 6-Comparison of copper flotation recovery profiles as a function of ASCu mill head grade (Beaumont, 2016)

recovery in the sulphide circuit, the mixed float process still returned a lower recovery for this ore type. Therefore, using a fixed ASCu cut-off grade of $0.05 \%$ to direct sulphide ore to the mixed float process was not reliable.

From the analysis and understanding of the oxidation domains, discussions between the geology and metallurgical teams revealed that each of the mineral groupings identified was more or less amenable to a specific mineral processing method employed at the Kansanshi metallurgical plant. A hypothesis was presented stating that copper recovery in each mineral processing circuit is a function of the ratio of ASCu to $\mathrm{TCu}$ grade. To investigate this hypothesis, head grade and recovery data for the sulphide and mixed float processing circuits spanning a four-year period was analysed to compare the recovery profiles for each circuit as a function of the calculated oxidation ratio (Figure 7). Through the recovery modelling process three key trends were identified:

> Ore with an oxidation ratio $<10 \%$ would produce more copper through the sulphide plant compared to the mixed and oxide plants

$>$ Ore with an oxidation ratio of $>10 \%$ but $<36 \%$ would be most effectively treated in the mixed float plant

$>$ Ore with an oxidation ratio $>36 \%$ would produce the highest recovery through the oxide plant.
The cross-over points at $10 \%$ and $36 \%$ oxidation ratio, as indicated in Figure 7, for the metallurgical recovery models were well aligned with the same ratio groupings derived from the analysis of raw geological sample data. It was found that the two separate analyses of separate data sources were aligning well to support the overall hypothesis that oxidation was the key factor in ore classification and metallurgical efficiency.

Further analysis of the available metallurgical data demonstrated two significant opportunities to recover additional copper from the mixed float and oxide ore. The first required a modification to the oxide flotation circuit, incorporating CPS technology to increase the recovery of minor secondary sulphide minerals such as chalcocite and covellite. The second required the mixed float ore tailings to be directed through the oxide leach circuit. A comparison of the oxidation ratio of mixed float mill head grade (prior to flotation) with the oxidation ratio of the mixed float tailings (after flotation) is presented in Figure 8. It was found that as copper-bearing sulphide minerals were recovered in the flotation process, the $\mathrm{ASCu} / \mathrm{TCu}$ ratio of the remaining tailings was increased, indicating that the minerals remaining in the mixed float tailings were more amenable to leaching. By directing the mixed float tailings through the oxide leach circuit the oxidized minerals could be leached and processed through to the SX-EW circuit.

\section{Gangue acid consumption}

Across the industry, managing the consumption of sulphuric acid in an oxide leach plant has always been a serious issue for most metallurgical operations. Typically at Kansanshi the highest grade oxide ore was found in close proximity to a lithological unit termed the 'upper marble', composed of calcium carbonate $\left(\mathrm{CaCO}_{3}\right)$ which is a gangue acidconsuming (GAC) component of the oxide ore. To limit the acid-consuming properties of oxide ore fed to the metallurgical plant, a limit of $50 \mathrm{~kg} / \mathrm{t} \mathrm{GAC}$ was applied by the Mat-Type ore classification system. With an abundance of cheap sulphuric acid being generated from the smelting process, the oxide ore processing strategy could be changed because acid consumption had become less of a constraint. It was therefore important to understand the geological range of

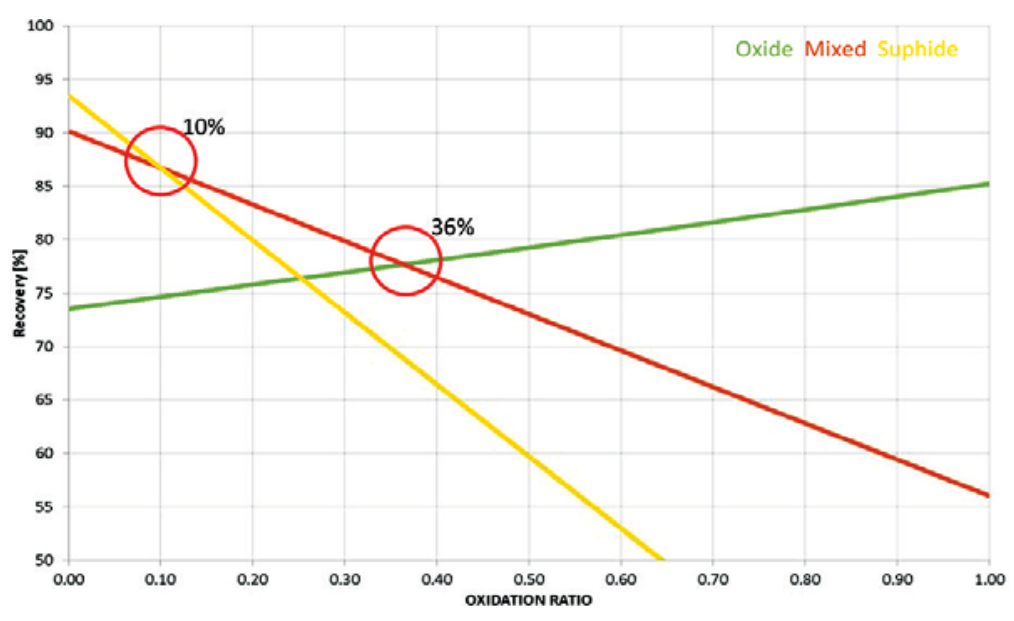

Figure 7-Process plant recovery with respect to oxidation ratio 


\section{Application of geometallurgical modelling to mine planning in a copper-gold mining operation}

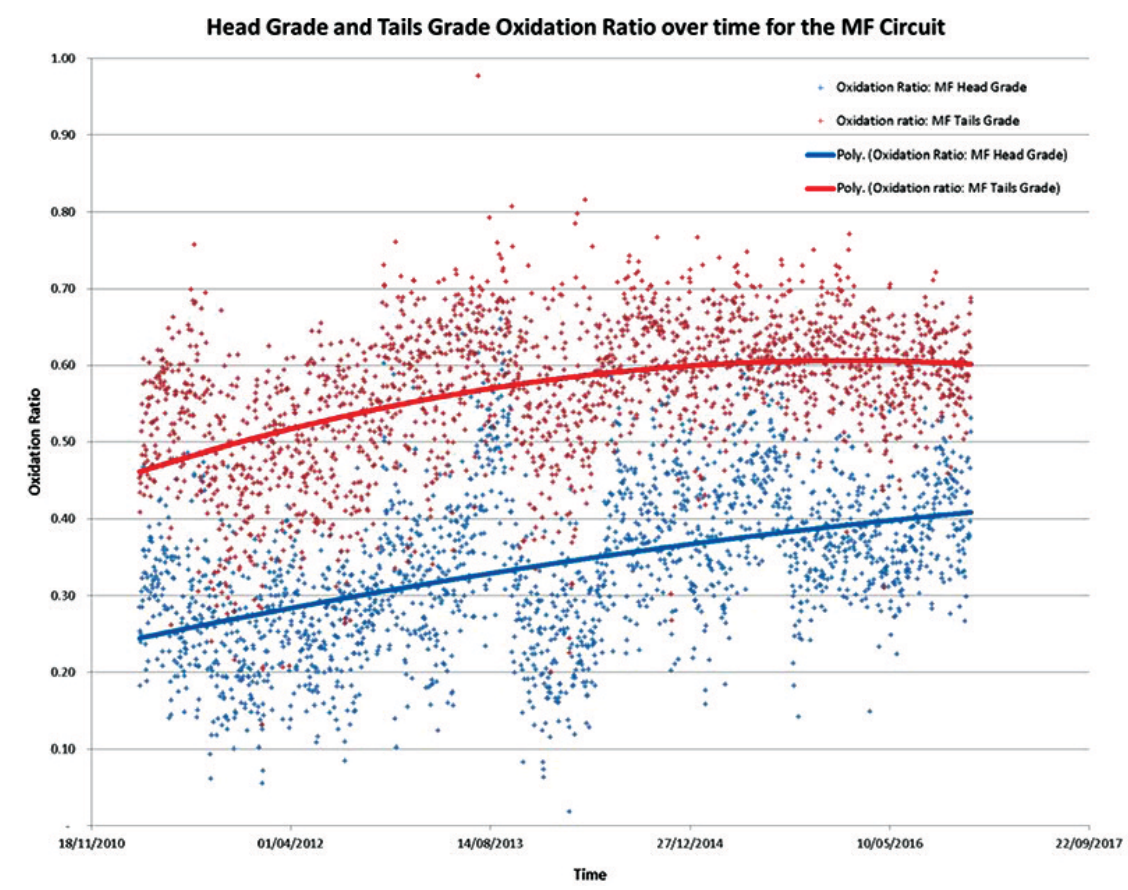

Figure 8-Comparison of head grade and tails grade oxidation ratios over time for the mixed float ore metallurgical process (Dawson and Beaumont, 2017)

gangue acid-consumers occurring naturally in the deposit and how best to control the feed of high-GAC ore types to the oxide circuit.

A review of the available geological assay data showed a highly skewed bimodal population of GAC data across the deposit (Figure 9). There are two distinct domains of GACbearing ore within the Kansanshi deposit. These can be geologically defined as:

> High-GAC domain, $>110 \mathrm{~kg} / \mathrm{t}$, dominated by marble

> Low-GAC domain, <110 kg/t, dominated by clastic rocks composed of schists and phyllites.

This analysis demonstrated that the limit of $50 \mathrm{~kg} / \mathrm{t} \mathrm{GAC}$ currently applied to oxide ore in the Mat-Type classification system was suboptimal, as it lay in the middle of one population of the GAC data. By raising the oxide ore GAC limit from $50 \mathrm{~kg} / \mathrm{t}$ to $110 \mathrm{~kg} / \mathrm{t}$ the acid consumption could be more appropriately managed through the application of geological controls. The net effect of this was that a significant quantity of oxide ore was now available for processing that would have previously been directed to stockpiles. With this increased quantity of oxide ore at a higher GAC content, a larger quantity of acid produced from the smelting process could be utilized.

\section{Acid to ore ratio}

Further investigation into the application of GAC management methods in the Mat-Type ore classification system revealed that it was possible to take advantage of the acid to ore ratio (AOR) factor. The AOR is a metallurgical factor developed to further define and manage the gangue acid consumption in the oxide ore metallurgical process, and is defined by Equation [2].

$$
A O R=\left(\frac{G A C}{A S C u}\right) * 0.1
$$

Equation [2] assumes that oxide ore with a high $\mathrm{ASCu}$ grade and a GAC greater than $50 \mathrm{~kg} / \mathrm{t}$ could still be fed to the oxide process plant if the AOR was below a nominal value set at five. However, if the AOR was above five the Mat-Type ore classification system indicated that the ore should instead be fed to the mixed float circuit.

An analysis of GAC and ASCu grade data demonstrated that there was no statistical relationship between GAC and $\mathrm{ASCu}$ grade. Furthermore, the application of the AOR at various stages of the Mat-Type ore classification system was directing oxide ore to either the wrong metallurgical process (mixed float) or to long-term stockpiles. The unintentional effect of this was to artificially increase the ASCu grade of the mixed float ore feed by changing the dominant mineralogical suite from secondary sulphide minerals to oxide minerals. Oxide minerals are less amenable to the CPS process than secondary sulphide minerals, thus while the factor was assisting in reducing the GAC content of the oxide circuit, there was a negative impact on the recovery of copper in the mixed float circuit.

\section{Mixed float AlCu ratio}

After the implementation of the Mat-Type ore classification system in 2009 a drop in the recovery performance of the mixed float process was noted. Metallurgical test work by Paquot (2009) had demonstrated that the recovery in the mixed float process could be improved by controlling the quantity of $\mathrm{AICu}$ in the feed. $\mathrm{AICu}$ is defined by Equation [3]:

$$
A I C u=T C u-A S C u
$$

$\mathrm{AICu}$ is effectively the portion of a primary or secondary sulphide mineral that has not been fully oxidized to become acid soluble. To improve and maintain recovery of the mixed float ore the 'mixed float acid insoluble copper ratio' (MF_AICu_Ratio) was developed as given by Equation [4]. 


\section{Application of geometallurgical modelling to mine planning in a copper-gold mining operation}

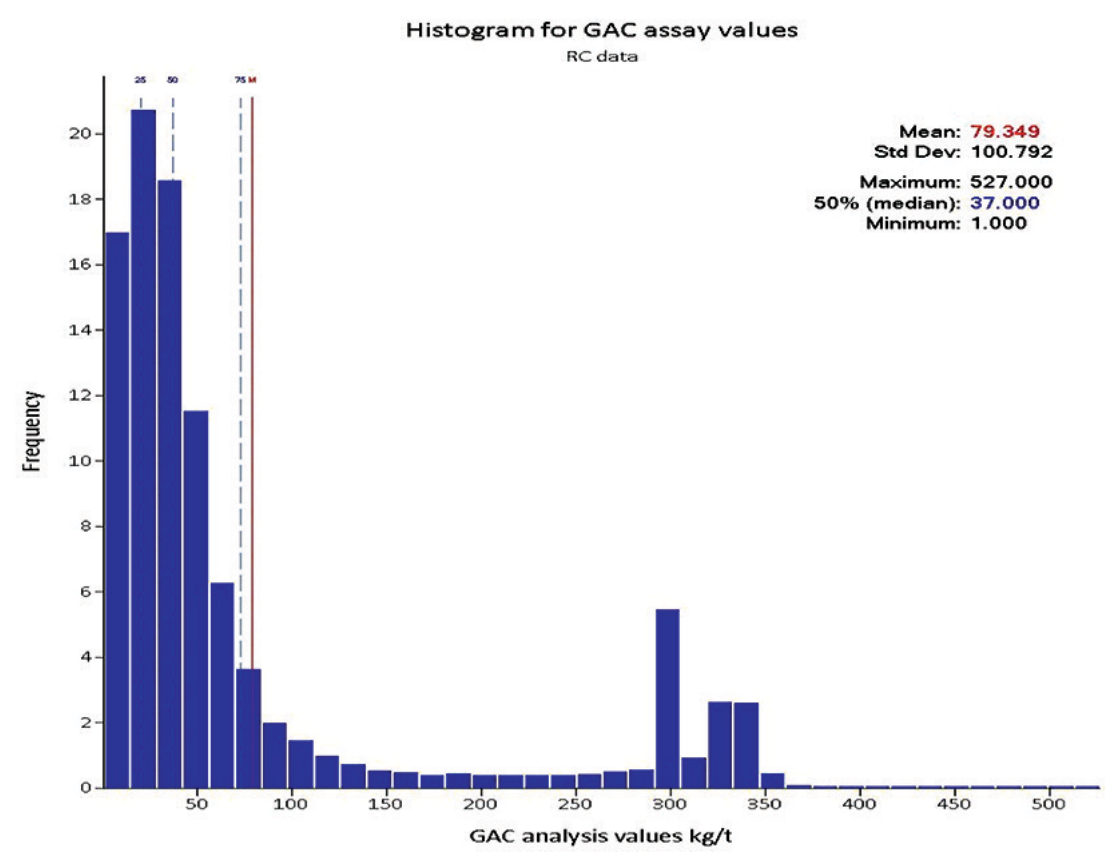

Figure 9-Histogram of GAC values for the Kansanshi deposit (Beaumont, 2016 after Ogilvie, 2014)

$$
M F_{-} A I C u_{-} \text {Ratio }=\left(100-\left(\frac{T C u-A S C u}{T C u}\right) * 100\right)
$$

The work by Paquot (2009) had demonstrated that a MF_AICu_Ratio of $>70 \%$ in the mixed float ore feed would improve the recovery. A revision was made to the Mat-Type ore classification system in 2010 to apply the MF_AICu_Ratio to the classification criteria of mixed float ore. Mixed float ore that did not meet the MF_AICu_Ratio criterion was directed to long-term stockpiles.

Despite the MF_AICu_Ratio being determined through a logical analysis of available metallurgical data, its application to the Mat-Type ore classification system was done in isolation from other factors applied to the same ore types. Therefore, it did not account for the varied range of mineralogy in the mixed float ore feed, nor the misclassification and redirection of high-GAC oxide ore to the mixed float circuit through the application of the AOR factor. While the MF_AICu_Ratio minimized the impact of poorly classified oxide ore entering the mixed float process, it was a reactive solution that did not prevent oxide ore from being incorrectly classified at source in the pit.

\section{Cut-off grades}

During the review of the Mat-Type ore classification system it was found that a series of fixed grade limits was applied to each of the 22 ore types as part of the process of determining whether the ore should be processed or stockpiled. These grade limits were linked to the perceived capabilities of the metallurgical process plant at a specific point in time. A mechanism was required to ensure that strategic decisions taken in the long-term planning environment would translate to short-term mine planning and execution. This would allow for economic cut-off grades determined in the Mineral Resource to Mineral Reserve conversion process to be updated as and when they changed, thus gaining alignment between all of the different technical facets of the business.

\section{Development of a new ore classification system based on geometallurgical modelling}

As a result of the analysis of oxidation ratios, plant recovery models, gangue acid consumption, AOR, MF_AICu_Ratio, and cut-off grades it was necessary to overhaul the Mat-Type ore classification system in order to develop a more optimal ore classification methodology. The 'OXMAT' system was developed with the goal of applying it to the ore control process at Kansanshi to supersede the Mat-Type system. A flow chart detailing the newly developed 'OXMAT' ore categorization methodology is provided in Figure 10.

The first step in revising the ore classification method and creating the OXMAT system was to group ore into representative geological domains. Oxidation ratios were calculated based on the estimated TCu and ASCu block grades of the geological model. Ratio ranges were then applied to the grade control block model, creating three main mineralization categories as follows:

> Sulphide float ore: oxidation ratio $<0.1$, fresh, unweathered, un-oxidized chalcopyrite

$>$ Mixed float ore: oxidation ratio $>0.1$ and $<0.5$, secondary sulphides minerals, partial or weak weathering, localized moderate oxidation

$>$ Oxide leach ore: oxidation ratio $>0.5$, moderate to intense weathering, moderate to intense oxidation.

The second step was to define more appropriate cut-off grades for each of the three categories. These cut-off grades would be required for separating waste from marginal ore, low-grade ore, and high-grade ore in each of the three broad ore categories. The cut-off grades derived from the Mineral Resource to Mineral Reserve conversion process were applied to the new grade-control ore classification system. This brought alignment to the various levels of business planning and assisted in day-to-day ore production and blending requirements. Critical to the management of cut-off grades was the development of a formalized periodic review process 


\section{Application of geometallurgical modelling to mine planning in a copper-gold mining operation}

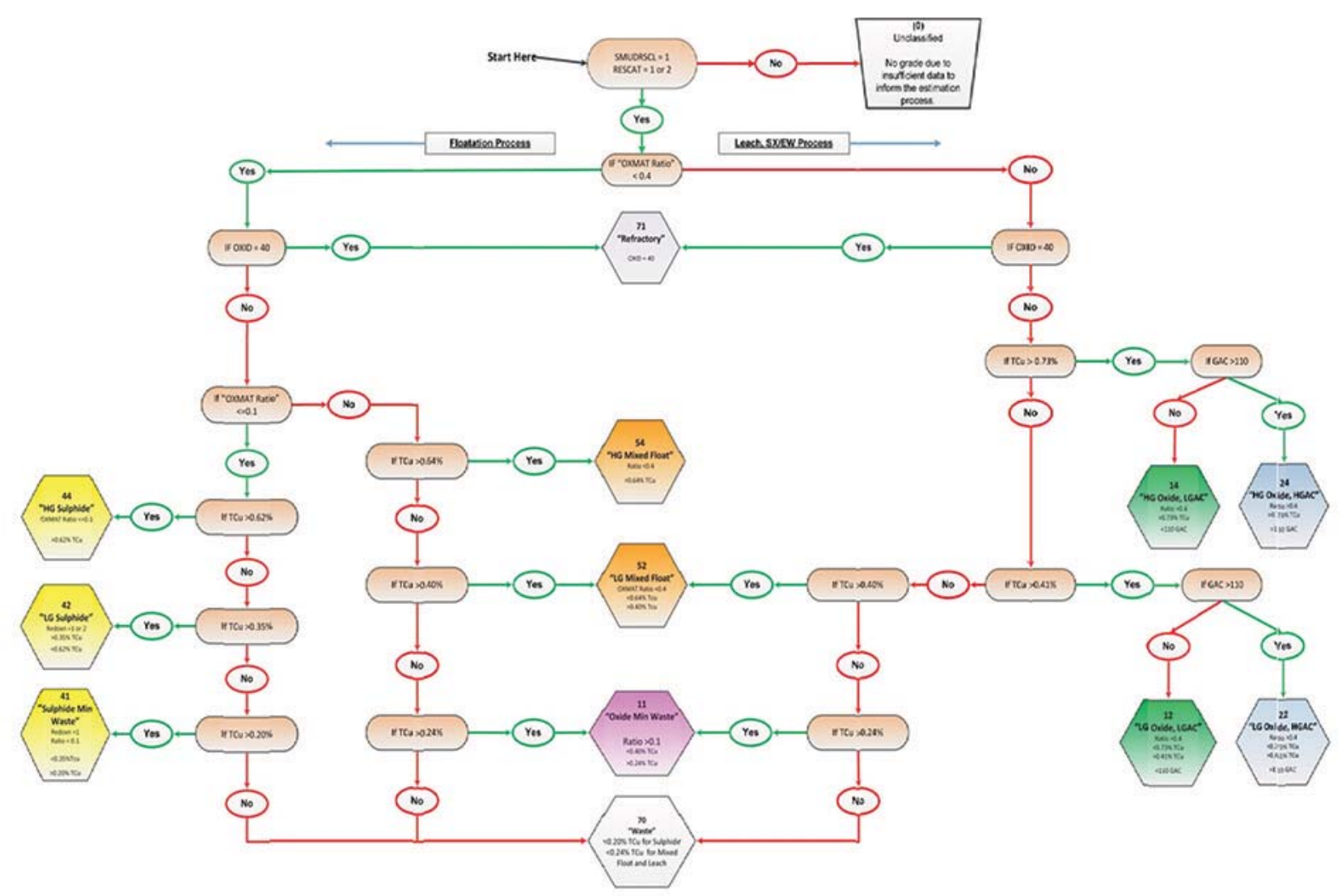

Figure 10-Flow chart representing the calculation logic of the newly developed OXMAT ore classification system

that would allow necessary adjustments to the cut-off grades based on changing economic parameters.

The final development in the new OXMAT ore classification methodology was to place an appropriate limit on gangue acid consumption in the oxide leach plant by using a geological limit that distinguished ore within the marble lithology from ore hosted in the clastic lithologies. Ore with a GAC $>110 \mathrm{~kg} / \mathrm{t}$ would be directed to the long-term stockpiles and recovered as and when there was sufficient acid available from the on-site smelter, while oxide ore with a $\mathrm{GAC}<110 \mathrm{~kg} / \mathrm{t}$ was directed straight to the oxide float/ leach plant and processed. The resulting ore classification method now contained only 13 categories compared to the 22 categories originally created in the Mat-Type system.

\section{Results from applying the revised ore classification system}

Once all the revisions had been incorporated in the ore classification methodology it looked very different to the original Mat-Type classification system. A total of nine ore categories could be completely removed, making the new OXMAT system far more manageable and easy to understand. The remaining 13 ore categories were redefined to classify ore more optimally at source, for feeding to the metallurgical process plant. A testing process was implemented to compare the ore and waste volumes defined by the two very different systems.

The OXMAT ore classification system was applied to a copy of the geological model in conjunction with the MatType system. Using survey data, the volume of material mined from the deposit between January 2013 and December 2015 was analysed to determine the quantities of ore and waste classified by Mat-Type and by OXMAT. Figures 11 and 12 present the results of this analysis, which indicated the following.

> Tonnes of waste defined by the OXMAT method were $19 \%$ less than the tons of waste defined by 'Mat-Type'

> Within the volume analysed only $8 \%$ of the material was considered as ore suitable for direct feed to the process plant using the Mat-Type method. However, when it was classified using the OXMAT method, ore suitable for direct feed to the process plant increased by $25 \%$

> Despite the substantial increase in the quantity of ore available for direct feed to the process plant using the OXMAT system, the quantity of ore directed to longterm stockpiles remained nearly the same as with classification using the Mat-Type method.

Through the application of the OXMAT ore classification method, further possible benefits were identified:

$>$ Less material would need to be mined to provide the same quantity of ore feed to the process plant, leading to the opportunity to reduce mining costs

> The ore feed was now consistently classified, thus removing the need for manual re-directions to be made on a daily basis

> Improved ore quality for all three metallurgical circuits would lead to higher copper recoveries, increasing the value derived from the deposit. 


\section{Application of geometallurgical modelling to mine planning in a copper-gold mining operation}

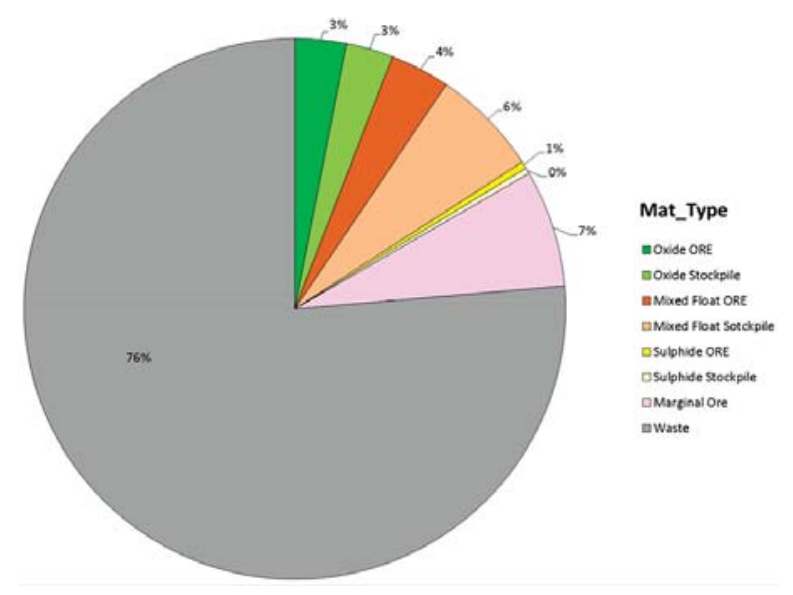

Figure 11-Relative proportions of ore and waste defined by the MatType system within the volume of material analysed

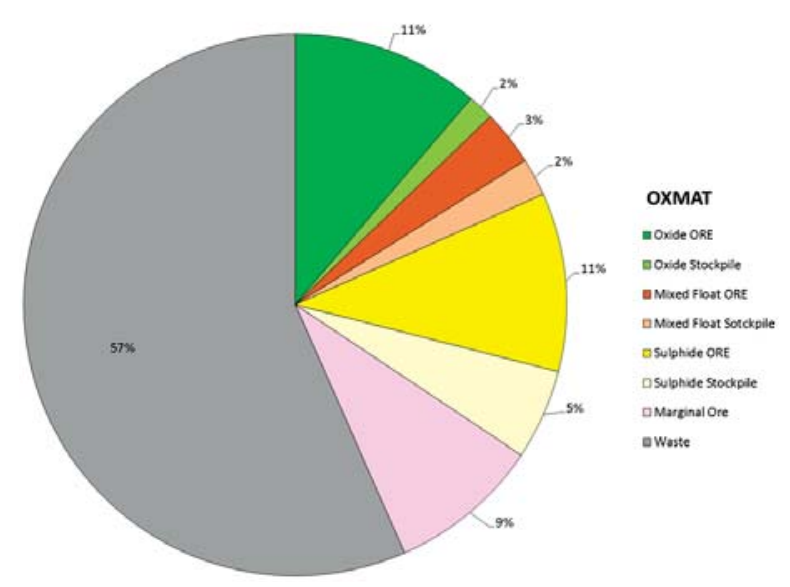

Figure 12-Relative proportions of ore and waste defined by the OXMAT system within the volume of material analysed

Within the volume of ore that was analysed the change in classification method did not directly reduce the quantity of ore going to long-term stockpiles, as was originally intended. It is, however, reasonable to assume that less ore would be directed to long-term stockpiles in the future if the overall annual mining volume is reduced.

The implementation of a geometallurgical methodology for ore classification and mine planning promoted the development and integration of knowledge between different technical disciplines across the mine value chain. Problems and challenges that arise during day-to-day operations can now be quickly understood and discussed within a large multi-disciplinary team, leading to effective decision-making which maximizes the flow of value along the mine value chain. Through this more collaborative approach that crosses traditional technical boundaries, the OXMAT system assists in achieving a more effective mine planning process, informed by geometallurgical analysis of the available data and centred on the overall mine value chain from the geological resource through mining, mineral processing, and smelting.

\section{Conclusions}

Variable ore characteristics pose a challenge in the mining industry as they have a direct impact on the mine-to-mill design, planning, and operation by reducing the mining and mineral processing efficiencies. It is therefore important to have a good understanding of the variability in ore characteristics. Geometallurgical modelling is an integrated approach that assists in overcoming these challenges and generates value-add for an operation. In this paper we presented a case study on geometallurgical modelling for a copper mine producing by-product gold, and provided a review of an ore classification system that was modified through geometallurgical modelling to improve process efficiencies and unlock value. The ore classification system called Mat-Type initially classified the various ore types ranging from 'poor quality' to 'good quality' into 22 different quality categories. Due to a lack of proper integration between the technical operating silos that formed the mine value chain, the Mat-Type system did not adequately consider geological, mineralogical, or metallurgical processes in an integrated way. The system was modified to produce a new geometallurgical ore classification system called OXMAT. Through the application of geometallurgical modelling, nine of the 22 ore categories in the original Mat-Type ore classification system were eliminated. The remaining 13 ore categories were re-defined in the OXMAT system in order to more appropriately classify the ore. By determining a more accurate and consistent set of ore definitions, it was possible to significantly increase the quantity of ore available for direct feed to the process plant, thus demonstrating the value-creating opportunities that can arise out of proper implementation of geometallurgical modelling.

\section{Acknowledgments}

The work reported in this paper is part of an MSc research study by the first author undertaken in the School of Mining Engineering at the University of the Witwatersrand. Permission by the management of First Quantum Minerals Ltd to publish the paper is greatly acknowledged.

\section{References}

BEAUMONT, C. 2016. A geo-metallurgical strategy for improving ore quality and mineral processing efficiency at Kansanshi mine in Zambia. MSc Research Report, University of the Witwatersrand.

BEAumont, C. 2017. Analysis of oxidation ratios in RC and diamond drilling data, a revision in the context of the current OXMAT ore classification. Internal company report. First Quantum Minerals Ltd., October 2017.

Broughton, D. and Hitzman, M. 2002. Exploration history and geology of the Kansanshi copper (minor gold) deposit Zambia. Economic Geology Special Publication no. 9. pp. 141-153. Society of Economic Geologists.

BYE. A.R., 2011. Case studies demonstrating value from geometallurgy initiatives. Proceedings of GeoMet 2011: The First AusIMM International Geometallurgy Conference, Brisbane, QLD, Australia, 5-11 September, 2011. David, D. (ed.), Australasian Institute of Mining and Metallurgy, Melbourne. pp.9-30.

Chibaya, A. 2013. Geo-metallurgical analysis - Implications on operating flexibility (A case for geometallurgy for Orapa A/K1 deposit). MSC Research Report, University of the Witwatersrand.

Dawson, P. and BEAumont, C. 2014. Defining variable recovery models using oxidation ratios. Internal company report. First Quantum Minerals Ltd. December 2014.

Dawson, P. and Beaumont, C. 2017. A review of Mixed Float tails processing and its impact on oxide leach efficiency. Internal company report. First Quantum Minerals Ltd. August 2017.

OGILVIE, J. 2014. Spatial analysis of GAC assay data for the Kansanshi deposit. Internal company report. First Quantum Minerals Ltd., November 2014.

PAQUOT, F. 2009. The influence of sulphidisation, the addition of dispersant and de-sliming of oxidised ore, on the recovery of the AICu component of mixed float ores. Internal company report. First Quantum Minerals Ltd. May 2009.

Sillitoe, R.H., Perello, J., Creaser, R.A., Wilton, J., Wilson, A.J., and Dawborn T. 2017. Age of the Zambian Copperbelt. Mineralium Deposita, vol. 52, no. 8. pp. $1245-1268$,

WooD, D. 2011. Geological mapping and interpretation of the Kansanshi Dome, Solwezi, North-western Province, Zambia. Internal company report. First Quantum Minerals Ltd. October 2011. 